\title{
Faktorar som påverkar kvaliteten på digital undervisning
}

\author{
M Fojcik, Høgskulen på Vestlandet \\ MK Fojcik, Høgskulen $i$ Volda
}

\begin{abstract}
Digitalisering av undervisningssektoren har fått mykje oppmerksemd dei siste månadane etter at samfunnet blei stengt. På grunn av smittevernreglar som avgrensar mogelegheita til fysisk undervisning, må utdanningsinstitusjonane tilpasse undervisninga til romkapasiteten, talet på studentar og ressursbruk til lærarane. Det medfører utfordringar for både studentar, lærarar og administrasjonen.
\end{abstract}

Dette konferansebidraget skal presentere resultat (erfaringar og refleksjonar) sett gjennom fire perspektiv: pedagogisk, sosial, økonomisk og økologisk. Kva slags digital undervisningsform trivst studentane best med? Kva gir størst læringsutbytte? Korleis blir det sosiale framheva gjennom undervisninga? Er studentane motiverte ved å sjå på ein skjerm? Kor mykje kostar utstyr som trengst til å førebu og gjennomføre digital undervisning? Kva er kostnaden på miljøet for å legge til rette for digital undervisning?

Studien presenterer ei samling av desse fire perspektiv og drofter om å drive digitale undervisningsformer. Både med tanke på den økonomiske kostnaden til institusjonane og kvar student, med den pedagogiske, sosiale og økologiske kostanden. Det er ein samla vurdering av pengar, tid, ny kunnskap og energi som kan gi eit fullstendig bilete av kor mykje det eigentleg kostar med digital undervisning. Kan vi forbetre undervisningskvalitet med avgrensande resursar?

\section{KVALITET PÅ DIGITAL UNDERVISNING}

I 21. århundre blei det innført fleire endringar og modifiseringar blant anna innanfor utdanning og læring. Dei siste åra har mange institusjonar og bedrifter jobba med digitalisering. Etter covid-19 pandemi har denne prosessen blitt meir sentral over heile verda. Mange institusjonar hadde ikkje oppnådd eit høg digitaliseringsnivå før det blei nødvendig å snu om på undervisninga og gå over til heildigitale former. Det blei ofte behov for å halde fram med undervisninga på ein eller anna måte, sjølv om utstyret, ressursar og førebuing har ikkje vert av god kvalitet. Forelesarar og instruktørar over heile verden blei nøydd til å undervise med dei ressursane dei hadde tilgjengeleg utan å få tid til å førebu noko anna eller reflektere kva slags kvalitet vil den digitale undervisninga oppnå.

Kvalitetomgrepet i dette bidraget blir definert som ein grad av eigenskapar eit fenomen oppfyller i møte med forventingar og krav (Kunnskapsdepartementet, 2016). Denne graderinga har «blitt et hønnørord som til stadighet brukes» (Utdanningsforbindet, 2019, s.6). Kva som avgjer god kvalitet kan variere, samt kva slags eigenskapar er nok til å dekke eit standard. Spesielt i undervisningssamanheng kan det vere vagt kva som kjenneteiknar kvalitet. «Universitetene og høyskolene skal gi god utdanning som tilfredsstiler fastsatte standarder og krav til kvalitet, og som de kontinuerlig søker å utvikle og forbedre» (Kunnskapsdepartementet, 2016, s.15). Diskusjonen om kva som er klassisk undervisning av god kvalitet er svært brei og har vore diskutert lenge. Debatten om kva som er god kvalitet på digital undervisning har no også blitt diskutert når all undervisning blei omforma til digital undervisning. Det finst fleire fordommar og forventingar om digital undervisning som ikkje er sanne, men som fører til at forelesarar er skeptiske eller negative til å ta i bruk denne forma før det viste seg at dette var nødvendig. Alt dette til saman fører til at situasjonen med digital undervisning er ofte ikkje slik mange tenker det er.

Etter eit par månader med pandemi har mange endra sin praksis. Fleire forskarar unders $\varnothing$ kte både positiv og negativ påverking av digital undervisning. Det finst rapporter skrive av universiteta som skildrar situasjonen med digitalisering i høgare utdanning og studentane og forelesarane sine meiningar og opplevingar av digital undervisning (Fojcik et al., 2020). 


\section{PEDAGOGISKE FAKTORAR}

Digitalisering av all undervisning har mange stader blitt innført veldig kjapt, for å halde fram med undervisninga. Denne hastigheita førte til at førebuing av ressursar og kunnskap om digital undervisning blei avgrensa. Undervisninga som blei gjennomført før (tavleundervisning, seminar, prosjektarbeid, laboratoria, Øvingar) blei erstatta med ein lærar framfor ein skjerm, utan meir variasjon. Studentane blei fråteken den fysiske kontakten med forelesarar, andre studentar og institusjonens fasilitetar. I standen for eit sosialt læringsmiljø med interaksjonar og faglegediskusjonar, blei all undervisning blitt til ei overføring av lærarens stemme og skjermdeling. Alle didaktiske handlingar og grep frå klasserommet forsvann eller blei avgrensa i det undervisninga flytta seg til forelesing via konferanseprogram eller til asynkrone opptak av forelesaren. Studentane måtte bli fort kjent med denne nye undervisningsmåten, der alt er digitalt, der det ikkje er mogeleg å snakke med sidemannen som tilfeldig sitt ved sidan av, eller diskutere kort ei oppgåve i grupper før dette blir gjennomgått i plenum. Den digitale undervisninga blei i stor grad styrt av lærarens monopol og einsidig overføring.

Førebuing av pedagogisk og didaktisk undervisning gjennom digitale former krev tid, ressursar og nye ferdigheitar. For å erstatte klassisk undervisning med presentasjon, trengst det utstyr som kamera, mikrofon, datamaskin, internett tilgang og programvare som er eigna for digital undervisning. Eit rom med konferansesystem både kostar svært mykje og har mogelegheit til å blir brukt av ein person om gangen. Når all undervisning på campus blir digital, er det upraktisk med konferansesystem. For mange institusjonar har løysinga vert å kjøpe programvare som kan fungere på vanlege datamaskiner (med kamera og mikrofon) og som kan vere tilgjengeleg for mange samtidig (til dømes Zoom eller Teams).

For å gjennomføre seminar, Øvingar, diskusjon, laboratoria og gruppearbeid, er det tilrådeleg å ha tilleggsutstyr i programvare til dømes greenbox, touch-screen, mobile kamera med program for datamaskin, OBS, kraftig grafikkort på PC og fleire dataskjermar. Det vil ikkje automatisk medføre betre kvalitet på undervisning og læring, men det kan gi mogelegheit for å utnytte potensialet til tekniske verktøy. Studentane får ikkje ei betre læringsutbytte når ein forelesar bytter om skjermdeling annakvar minutt, (mens private filer blir tilfeldigvis vist imellom), e-post meldingar som dukkar plutseleg opp på skjermen midt i ein presentasjon, eller at forelesaren blir oppringt på datamaskinen eller andre digitale tenester. Det er lett å miste konsentrasjon og motivasjon når ein stadig observerer at forelesaren har utfordringar med å igangsetting av lyd/mikrofon/høgtalarar, start på opptak eller når ein ikkje finner riktige dokumenter til deling.

\section{SOSIALE FAKTORAR}

I sosiokulturell læringsteori blir det lagt stor vekt på språk og sosiale interaksjonar som handlingar til å fremje læring (Säljö, 2013). Med dette blikket på læring er det mykje som blir annleis når undervisninga blir heildigital. Den sosiokulturelle læringsteorien påpeiker at relasjonar mellom elevar og lærarar påverkar begge partar, sjølv om begge partane kan ha eit anna synspunkt på same situasjon (Lyngsnes \& Rismark, 2014). Denne teorien tar for seg den sosiale delen av menneskelege behov og bygger på relasjonar kvar elev har til læraren og læring generelt. Altså at ein kan lære både gjennom det å utrykke seg sjølv og å høyre korleis andre formulerer sitt kunnskap. Det betyr også at graden av læring er avhengig av menneskelege forhold og læringsmiljøet. I eit kontekst der undervisning skjer einsidig, eller der det er utfordrande med kommunikasjon i læringsmiljøet, blir det fort vanskeleg å halde konsentrasjon og fokusere på læringsutbytte.

Eit anna pedagogisk faktor er å snakke til skjermen i lange økter. Mangel på tosidig kommunikasjon og støtte kan vere forstyrrande for studentar og slitsamt i lengda. Utan tilbakemelding, både verbal og ikkje verbal, veit ikkje forelesaren kva utfordringar kan studentane møte i undervisninga. I eit klasserom kan ein ta eit kjapp blikk over studentane i salen for å reflektere i kor stor grad har det fått med seg innhaldet, men om undervisninga er digital, og studentane sitt utan kamera og med avstått mikrofon, er det vanskeleg for forelesaren å vite om tempo på gjennomgangen er passande eller er det behov for endring. Siste unders $\varnothing$ kingar viser at mange studentar er beviste om denne situasjonen, men vel å ikkje gjere noko med det. Metodar som «learning by doing» funnet by Dewey er vanskelege å overføre til digital undervisning. Utan at både læraren og studentane veit nøyaktig kva alle gjer, er det vanskeleg å bidra med god forklaring eller rettleiing. 
Korleis kan ein aktivisere studentane? Kva oppgåver er interaktive, og korleis kan ein lærar kan motivere studentane til gruppearbeid og til sjølvstendig arbeid? Det er viktige spørsmål innan høgare utdanning. Lærarar bør stadig utvikle seg, prøve nye ting, verktøy og arbeidsmåtar og dele erfaringar med kvarandre. Det finst fleire tilleggsverktøy og programvare som Padlet, Kahoot, Gather, videosamtale, digitale øvingar og prosjektarbeid som kan brukast for å støtte interaksjonar i klassen og bidra til ein meir sosial læringsmiljø. Samt enklare tilgang til læraren og mogelegheit til å stille spørsmål og søke råd. Desse ressursar er tilgjengelege, men ein må først sette seg inn i kvart verktøy for å tilpasse didaktiske, pedagogiske og faglege behov til utstyret som kan brukast. Dette krev tid dermed ressursar.

\section{4 ØKOLOGISKE OG ØKONOMISKE FAKTORER}

Det finnes ei utbreidd oppfatning at digitalisering er både mykje billigare og mykje meir $\varnothing$ kologisk enn fysisk undervisning, spesielt når læraren eller studentane må reise langt for å bli med på undervisninga. Dessverre er det ganske vanskeleg å samle nøyaktig informasjon om straumforbruket på utstyr på grunn av store variasjonar gitt av produsentane og litteraturen. Det er også viktig korleis ein eining blir brukt. Dette bidraget undersøker kor mykje kostar og kor mykje CO2 er produsert i ved bruk av digitale undervisningsformer. Den nødvendige utstyr for å gjere det er: datamaskin (stasjonær eller berbar), belysning og internett.

Undersøkinga målte (ved hjelp av Lutron Power Analyzer DW6090) straumforbruket for nokre einingar i løpet av ei digital undervisningsøkt. På datamaskiner var det opna programvare som: Zoom, OBS, 2 kamera, touch-screen, Visual Studio, PowerPoint, NDI for real-time skjerm deling. Resultata er presentert i Tabell 1.

Tabell 1. Samanlikning av straumforbruk ifølge forskjellege kjelder.

\begin{tabular}{|l|l|l|l|}
\hline \multirow{2}{*}{ Eining } & \multicolumn{3}{|c|}{ Straumforbruk [W] } \\
\cline { 2 - 4 } & $\begin{array}{l}\text { Informasjon frå nett } \\
\text { (Energy } \\
\text { Calculator, u.å) }\end{array}$ & $\begin{array}{l}\text { Informasjon frå } \\
\text { produsent / maks. }\end{array}$ & Måling \\
\hline $\begin{array}{l}\text { PC: (i7, 64GB, 512 SSD, integrert } \\
\text { grafikkprosessor, 2* 27” skjerm }\end{array}$ & $100+30+30$ & $550+30+30$ & $115+33+25$ \\
\hline $\begin{array}{l}\text { Berbar 14" (i5, 16GB, 512SSD, } \\
\text { dockingstasjon, } \\
\text { grafikkprosessor + 2* 19" skjerm }\end{array}$ & $60+30+30$ & $135+30+30$ & $55+10+25$ \\
\hline Belysning (3x fluorescent lamp - 5500K) & $3 \times 14$ & $3 \times 45$ & $3 \times 40$ \\
\hline Ruter DECO M9 & 6 & 15 & 15 \\
\hline Saman & 328 & 955 & 398 \\
\hline
\end{tabular}

Det er synleg store forskjellar avhengig av utrekningsmetode. Så kor mykje energi krevjast ein 2-timers forelesning for 100 studentar på Zoom?

Studentane bruker ein rekke utstyr: frå vanlege datamaskiner til spelldatamaskiner, med rekke av programvare. Spelldatamaskiner (vanlegvis pga. grafikkortet og stor skjerm) bruker mykje meir energi enn andre typar. Standard berbar maskin har ofte ein liten skjerm som gjer dei enkle å bære, men forhindrar frå å sjå mange detaljer. PowerPoint presentasjon som er tydeleg synleg på læraren sin skjerm kan vere vanskeleg å lese på skjerm under 13" (mobil, små berbar datamaskin). Mange personar bruker ein ekstra skjerm til å jobbe heime for å sikre seg god lesbarheit. Vi antar at $1 / 3$ del av studentane bruker PC og resten bruker berbare datamaskiner eller telefoner. Vidare antar vi at 1/3 del av berbare maskiner brukar ein ekstra skjerm. Alle skal ha godt med lys der dei sitter, og alle skal ha minst ein Internett ruter. 
Tabell 2. Antatt energiforbruk

\begin{tabular}{|l|l|l|l|l|}
\hline Utstyr brukt & W/time & Tal på studentar & Timer & Straumforbruk \\
\hline PC & 100 & 40 & 2 & 8000 \\
\hline Monitor & 30 & 40 & 2 & 2400 \\
\hline Laptop & 50 & 60 & 2 & 6000 \\
\hline Monitor & 30 & 20 & 2 & 1200 \\
\hline Belysning & 40 & 100 & 2 & 8000 \\
\hline Ruter & 15 & 100 & 2 & 3000 \\
\hline Lærar (frå Tabell 1.) & 400 & & 2 & 800 \\
\hline & & & saman & 29400 \\
\hline
\end{tabular}

Tala i tabell 2. viser at ein 2-timers forelesning krev ca. $30 \mathrm{~kW}$ energi. I tillegg er det ein del kostnader for energi som trengs for dataoverføring mellom brukare, behandling, lagring og drift av datasentre. (Avgerinou, Bertoldi \& Castellazzi, 2017, Miller, 2020, Mytton, 2020). Det er kjent at hastigheit på transmisjon aukar proporsjonalt med energien som krevjast (Sodhro, Chen, Sekhari, Ouzrout \& Wu, 2018).

I eit fors $ø \mathrm{k}$ estimerer vi at ein 1-timers forelesning brukar cirka 250MB av data. I HVL ifølge nettsida (Høgskulen på Vestlandet, u.å) finnes det 131 linjer. Vi antar at alle linjer er på 3 år, alle har 3 fag per semester, kvar fag har 90 timer og berre 1/4 del av forelesning er lagra. Alt dette saman gir oss $6.6 \mathrm{~TB}$ per semester. Disse data lagrast eit sted og blir ofte lasta ned av studentane. Det finst ingen klare metodar for å måle eller estimere kor mykje energi krevjast for å lagre og hente desse data. Av denne grunn valte vi å fortsette berre med allereie utrekna kostnad på undervisning på $30 \mathrm{~kW}$.

Neste steg er å finne ut kor mykje CO2 ekvivalent tilhøyrar desse 30kW. Det er store forskjellar, avhengig av kor ein er i landet. I artikkelen har vi valt verdiar frå norsk nettside (Energi og Klima, u.å.). Data der er ikkje transparente på dokumentasjon og datainnhenting, men dei kan vere brukt som ei tilnærming til problemet.

I eksempelet vårt hentar vi inn data frå ein bilprodusent (Volkswagen AG, u.å.) om Volkswagen Golf GTE (hybrid) som bruker $40 \mathrm{~g} \mathrm{CO} 2$ per km. Denne bilen er brukt for å samanlikne mengde CO2 som blir brukt.

Tabell 3. Samanlikning av CO2 ekvivalent og distanse for identisk CO2 ekvivalent

\begin{tabular}{|l|l|l|l|}
\hline Land & $\begin{array}{l}\text { Tal på CO2 for } \\
1 \mathrm{KWh}[\mathrm{g}]\end{array}$ & $\begin{array}{l}\text { Tal på CO2 for 2 timer } \\
\text { forelesning }[\mathrm{g}]\end{array}$ & $\begin{array}{l}\text { Distanse som gir same tal på } \\
\text { CO2 for Golf GTE som 2- } \\
\text { timers forelesning [km] }\end{array}$ \\
\hline Norge - Vestlandet & 32 & 660 & 24 \\
\hline Polen & 712 & 21360 & 524 \\
\hline Tyskland & 402 & 12060 & 302 \\
\hline Verdens gjennomsnitt & 442 & 13260 & 332 \\
\hline
\end{tabular}

\section{DISKUSJON OG KONKLUSJON}

Basert berre på målbare utrekningar av direkte faktorar (utan å ta med energi til dataoverføring, fordi det er ikkje kjent korleis land overfører data, kor dei blir samla inn og kor mykje energi er brukt til oppbevaring eller til kjøling eller behandling (Shehabi et al., 2016), kan det estimerast at ei digital undervisnings $\varnothing \mathrm{kt}$ i mange land ikkje er så $\varnothing$ kologisk som det var oppfatta (McGovern, 2020). Sjølv om det er lite forureining i Norge kan CO2 komme utanfrå. Det er mogeleg at 2-timers digital undervisning 
brukar meir $\mathrm{CO} 2$ enn ein lærar som køyrer frå f.eks. Førde til Bergen (og tilbake) til ein fysisk forelesning.

Den økonomiske faktoren har ein anna påverking. Samanlikning av kostnader for energi $(\sim 0.15 \mathrm{NOK} / 1 \mathrm{~kW})$ og for bensin $(\sim 15 \mathrm{NOK} / 1$ liter $)$ viser at for Vestlandet vil tilsvarande energi kosta under $5 \mathrm{NOK}$ og bensin nesten $7 \mathrm{NOK}$. I andre land er differansen større. I Polen vil tilsvarande energi koste $20 \mathrm{NOK}$ og bensin 300NOK.

Kostnadene ved digitalisering er ikkje berre overføringskostnadene, men også kostnaden av maskinvare, programvare og arbeid til lærarane som jobbar og forbereder ei ny type undervisning. Dette har ofte skjulte kostnader. Å køyre digital undervisning er ikkje det same som å ha tavleundervisning med kamera. Det er vanskeleg å lage ein standard på kva slags undervisning er av betre kvalitet eller kva som er standard for digital undervisning. Det finst fordelar og ulemper med begge typar av undervisning. Gjennom koronatid var det periode med påbod å ha alt gjennom digitale undervisningsformer, men det har vore ei spesiell tid for alle. Det som er viktig at kvar gang ein skal planlegge undervisninga, bør alle faktorane bli tatt i vurderinga. Studentane har sine vaner og rutinar. Det er enkelte lærings- og undervisningsformer som dei likar betre enn andre, eller som dei er meir komfortable med. Lærarane har erfaring og pedagogisk kunnskap innanfor områder dei brukar og har tid til å unders $\varnothing$ ke og spesialisere seg innanfor. Administrasjon/leiing må planlegge alt og dekke kostnader og ressursar. Det er viktig å ha ein balanse og ikkje gløyme faktorar som kan påverke digital undervisning.

\section{REFERENCES}

Avgerinou, M., Bertoldi, P. \& Castellazzi, L. (2017). Trends in Data Centre Energy Consumption under the European Code of Conduct for Data Centre Energy Efficiency. Energies 2017, 10, 1470.

Brockfeld, T., Müller, B., \& de Laffolie, J. (2018). Video versus live lecture courses: a comparative evaluation of lecture types and results. Medical Education Online, 23(1), 1555434.

Energi og Klima (u.å.). Live-data: Strøm og Co2. Henta frå https://energiogklima.no/klimavakten/live-datastrom-og-co2

Energy Use Calculator (u.å) Henta frå http://energyusecalculator.com [tilgang 18.01.2021]

Fojcik, M., Fojcik, M. K., Hegland, P. A., Kyte, L., Midtbø, T. G., Pollen, B., Sande J, Sande, O. (2020). Praktisk digitalisering av høgskuleundervising. I Digital samhandling (pp. 321-335).

Høgskulen på Vestlandet (u.å). Studieprogram. Henta frå https://hvl.no/studier/studieprogram/studietilbod/

Kunnskapsdepartementet. (2017). Digitaliseringsstrategi for universitets- og høgskulesektoren. Henta frå https://www.regjeringen.no/contentassets/779c0783ffee461b88451b9ab71d5f51/no/pdfs/digitaliseringsstrat egi-for-universitets--og-hoysk.pdf

Lyngsnes, K. M., \& Rismark, M. (2014). Didaktisk arbeid: Gyldendal akademisk.

McGovern, G. (2020). The hidden pollution cost of online meetings. Henta frå https://gerrymcgovern.com/thehidden-pollution-cost-of-online-meetings/

Meld.St. 16 (2016-2017). Kultur for kvalitet i høyere utdanning. Henta frå https://www.regjeringen.no/contentassets/aee30e4b7d3241d5bd89db69fe38f7ba/no/pdfs/stm201620170 016000dddpdfs.pdf

Miller, R. (2020). Inside Zoom's Infrastructure: Scaling Up Massively With Colo and Cloud. Henta frå https://datacenterfrontier.com/inside-zooms-infrastructure-scaling-up-massively-with-colo-and-cloud

Mytton, D. (2020). How much energy do data centers use? Henta frå https://davidmytton.blog/how-muchenergy-do-data-centers-use

Shehabi, A., Smith, S. J., Sartor, D.A., Brown, R. E., Herrlin, M., Koomey, J. G., Masanet, E. R., Horner, N., Azevedo, I. L. \& Lintner, W. (2016). United States Data Center Energy Usage Report.

Sodhro, A. H., Chen, L., Sekhari, A., Ouzrout, Y., \& Wu, W. (2018). Energy efficiency comparison between data rate control and transmission power control algorithms for wireless body sensor networks. International Journal of Distributed Sensor Networks, 14(1), 1550147717750030. Henta frå https://www.researchgate.net/publication/322824835_Energy_efficiency_comparison_between_data_rate_c ontrol_and_transmission_power_control_algorithms_for_wireless_body_sensor_networks

Säljö, R. (2013). Støtte til læring - tradisjoner og perspektiver. In R. J. Krumsvik \& R. Säljö (Eds.), Praktisk Pedagogisk utdanning. Bergen: Fagbokforlaget.

Utdanningsforbundet (2019). Begrepet kvalitet - kva dreier det seg om? Henta fråhttps://www.utdanningsforbundet.no/globalassets/varpolitikk/publikasjoner/temanotat/2019/temanotat_2019.03.pdf

Volkswagen AG (u.å.) Vehicle. Henta frå https://www.volkswagenag.com/en/sustainability/environment/vehicle.html 